\title{
EFFECT OF HYDROTHERMAL TREATMENT ON THE PHYSICAL AND RHEOLOGICAL PROPERTIES OF MAIZE STARCHES
}

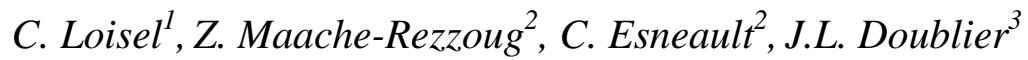

(1)Laboratoire GEPEA, ENITIAA rue de la Géraudière, BP 82225, 44322 Nantes Cedex 3, F

(2)Université de la Rochelle, Laboratoire LMTAI, av. M. Crepeau, 17042 La Rochelle, F

(3) UPCM-INRA, BP 71627, 44316 Nantes Cedex 3, F

Author to whom correspondence should be addressed

Z. Maache-Rezzoug

Université de La Rochelle - Pôle Sciences

Laboratoire "Maîtrise des Technologies Agro-Industrielles"

Avenue Michel Crépeau

17042 La Rochelle - France

Tel : $\quad$ (33) 0546458615

Fax : $\quad$ (33) 0546458616

e-mail : $\quad$ zrezzoug@univ-lr.fr 


\section{Abstract.}

Standard maize (SMS) and waxy maize starch (WMS) were hydrothermally treated at their residual moisture level $(\sim 12 \%)$ by Instantaneous Controlled Pressure Drop process in order to obtain pre-gelatinised starches in a single step. The effect of two parameters of this process, namely the steam pressure level and processing time, on the structural and rheological properties of the native maize starches were described. The occurrence of partial gelatinization for DIC treated starches was clearly attested by the increase of the median volume diameter in cold water, the decrease of the gelatinization enthalpy and a loss of birefringence under polarized light, this was more prominent for the highest pressure and longest time: 2.7 to 3 bar for 200 to 300 seconds. Sensitivity of starches to the process was also dependent on their origin, SMS being more affected than WMS.

Keywords : Hydrothermal treatment, Maize starch, Pregelatinization, Rheological properties 


\section{Introduction}

Starch is essential in many formulated foodstuffs. It constitutes an important source of energy and contributes to the structure and the texture of food, as a thickening or gelling agent. These properties occur under heating (pasteurization or sterilization) in an excess of water. Pregelatinized starches are widely used for many foods as a major ingredient to provide thickening texture at temperatures below the gelatinization temperature. They are obtained from native or modified starch, by drum (Vallous, Gavrielidou, Karapantsios \& Kostoglou, 2002), roll, or spray drying after cooking and also by extrusion cooking (Mercier, 1987). Annealing (Tester \& Debon, 2000) and heat-moisture treatment (HMT) (Gunaratne \& Hoover, 2002) are also two common physical means by which the treated starch can acquire modified properties without rupturing the granule. These processes require a hydration step followed by drying. When applying a thermal treatment, the initial dispersion is changed into a starch paste due to the swelling of granules and leaching of amylose in the intergranular phase. This overall phenomenon is referred to as the pasting process and is a result of the gelatinization which corresponds to the loss of crystalline starch granules at $\sim 60-70^{\circ} \mathrm{C}$. These overall changes include loss of birefringence, loss of X-ray diffraction pattern, absorption of water and swelling, change of shape and size of starch granules and leaching of amylose from the granules (Williams \& Bowler, 1982), (Eliasson \& Larsson, 1993), (Hoover, 2001).

Many methods of characterizing structural changes of starch upon pasting have been developed. A large number of techniques, such as differential scanning calorimetry (DSC) (Donovan, Lorenz \& Kulp, 1983; Lim, Chang \& Chung, 2001; Ziegler, Nordmark \& Woodling, 2003; Kiseleva, Tester, Wasserman, Krivandin, Popov \& Yurvev, 2003) and X-ray diffraction (Kiseleva et al., 2003; Lim et al., 2001) have been used to study the gelatinization behavior of starch granule altered by various physical treatments. During recent years differential scanning calorimetry (DSC) has evolved as the preferred method (Eliasson \& Larsson, 1993; Takaya, Sano \& Nishinari, 2000), to 
measure different aspects of the gelatinization process. DSC is of great value in studying both the loss of crystalline order during gelatinization, which occurs when the starch is heated in the presence of water (Cooke \& Gidley, 1992), and the re-ordering of such systems during ageing (Chung \& Lim, 2003).

Hydrothermal treatment of starch also leads to a modification of its rheological properties. These properties can be characterized after rehydration of the starches under mild temperature $\left(40^{\circ} \mathrm{C}\right.$, Anastasiades, Thanou, Loulis, Stapatoris \& Karapantsios, 2002) or using Brabender Viscogragh to assess repeatable pasting conditions. The shape of the pasting profile gives then useful indications on the ability of the granules to swell freely before their physical breakdown (peak and plateau values).

The purpose of the present work was to characterize hydrothermally-treated starches by a recent hydrothermal process: the Instantaneous Controlled Pressure Drop (DIC) over a useful range of operating conditions. The DIC process is based on the thermomechanical processing induced by subjecting the product to a rapid transition from high steam pressure to a vacuum. It has been used initially in the field of the drying texturation in order to obtain a more expanded structure than one obtained by classical methods such as hot air. This process was applied to various products such as pasta products (Maache-Rezzoug \& Allaf, 1999), and a thickening polysaccharide used in the petroleum industry, the scleroglucan (Rezzoug, Maache-Rezzoug, Mazoyer, Jeannin \& Allaf, 2000). The originality of the DIC treatment compared to other hydrothermal treatments is that the starches are treated at residual moisture content; no hydration step is then required before the DIC treatment.

The effect of process input variables (steam pressure level and processing time) on the structural and functional properties of two native starches, standard maize starch (SMS) and waxy maize (WMS) was investigated. 


\section{Materials and methods}

\subsection{Raw materials}

Standard maize starch (SMS) and waxy maize starch (WMS, Waxilys 200) were supplied by Roquette Frères (Lestrem, France). The amylose content was different for the two types of starch: $27-28 \%$ and lower than $1 \%$ for SMS and WMS, respectively.

\section{Methods}

\section{Moisture content}

The starch moisture content was determined by air oven at $105^{\circ} \mathrm{C}$ during $24 \mathrm{~h}$, according to the A.F.N.O.R. standard method.

\section{DIC hydrothermal treatment}

The schematic diagram of the equipment used has been described in a previous study (Rezzoug et al., 2000). This equipment is composed of three main elements: a processing vessel, a vacuum container and a valve that connects these two parts. In the DIC treatment, the sample is placed in a vessel which is maintained under vacuum ( 50 mbar). This initial vacuum allows a better diffusion of the heating fluid through the product and consequently heat transfer is improved. The feed of the treatment vessel was typically $150 \mathrm{~g}$ of native starch at residual moisture content $(\sim 12$ $\% \mathrm{w} / \mathrm{w})$.

The thermal treatment is performed by injection of saturated steam, at a fixed steam pressure for a determined processing time, followed by a rapid pressure drop to vacuum (about 50 mbar). The opening of the valve leads to a rapid transition from processing pressure to a vacuum because the volume of the vacuum container $(1600 \mathrm{~L})$ is 130 times larger than the one of the treatment vessel (12 L). The rapid transition of pressure inside the processing vessel induces a rapid cooling of starch from $107-140{ }^{\circ} \mathrm{C}$ (depending on the steam pressure level) to about $30^{\circ} \mathrm{C}$ in less than 1 
second. The equilibrium pressure after dropping pressure depends on the operating conditions: the higher the steam pressure level, the higher the equilibrium pressure. At the end of the treatment, the starch sample does not need a drying step because initial and final moisture are similar.

\subsubsection{Pasting procedure using Viscograph Brabender}

The processed samples are powdery products that have to be rehydrated for analytical purpose. This was performed using the Brabender Viscograph to obtain a starch paste under repeatable conditions. The starch concentrations were chosen in order to lie within the sensitivity range of the Viscograph: i.e. 6\% for SMS and 3\% (w/w) for WMS. Starch was slurried in demineralized water at room temperature, and then submitted to gradual heating $\left(1.5^{\circ} \mathrm{C} / \mathrm{min}\right)$ from $30^{\circ} \mathrm{C}$ to $96^{\circ} \mathrm{C}$; ; this temperature was maintained for 10 minutes and was followed by a cooling step $\left(1.5^{\circ} \mathrm{C} / \mathrm{min}\right)$ down to $70^{\circ} \mathrm{C}$ before sampling. The relevant values obtained from the pasting profile were: peak and plateau (at $96^{\circ} \mathrm{C}$ ) in Brabender units $(100 \mathrm{BU}$ for $25 \mathrm{cmg}$ ). The moisture content was determined directly after the pasting procedure, to check the starch concentration before rheological measurements.

\subsubsection{Rheological measurements}

Flow behavior and viscoelastic properties of starch pastes were measured using a controlled stress rheometer (TA Instrument AR1000) with the cone/plate geometry $\left(6 \mathrm{~cm} / 2^{\circ}\right)$. An aliquot of the starch dispersion pasted in the Viscograph Brabender was poured onto the plate of the rheometer preheated at $60^{\circ} \mathrm{C}$, then covered by a layer of paraffin oil to avoid evaporation. For flow measurements, two up-down shear scans from 0 to $660 \mathrm{~s}^{-1}$ (4 min each) were linearly applied, followed by a logarithmic stepwise decrease from 660 to $0.01 \mathrm{~s}^{-1}$, after equilibrium for each shear rate.

The oscillatory tests were carried out at $4 \%$ strain (linear viscoelastic range) on a new aliquot, with the following sequence: a mechanical spectrum at $60^{\circ} \mathrm{C}$, then a quenching to $25^{\circ} \mathrm{C}$, followed 
by a time dependent measurement of the viscoelastic behavior during 15 hours at $6.3 \mathrm{rad} / \mathrm{s}$, and a mechanical spectrum at $25^{\circ} \mathrm{C}$. The frequency range investigated was from 0.5 to $100 \mathrm{rad} / \mathrm{s}$.

\subsubsection{Differential scanning calorimetry}

The DSC analysis was performed directly on samples treated by DIC with the Setaram MicroDSCIII apparatus at a 70\% moisture content using the following procedure: gradual heating from 20 to $95^{\circ} \mathrm{C}\left(1^{\circ} \mathrm{C} / \mathrm{min}\right)$. From the DSC curves, the peak temperature $\left(\mathrm{T}_{\mathrm{p}}\right)$ and gelatinization enthalpy $(\Delta \mathrm{H})$ were calculated. The degree of gelatinization of hydrothermally treated starches was calculated by the following equation (Marshall, Wadsworth, Verma \& Velupillai, 1993):

$$
D G(\%)=\left(1-\frac{\Delta H_{t}}{\Delta H_{\text {raw }}}\right) \times 100
$$

where DG is the degree of gelatinization of hydrothermally treated starch, $\Delta \mathrm{H}_{\mathrm{t}}$ the gelatinization enthalpy of DIC treated starch and $\Delta \mathrm{H}_{\text {raw }}$ the gelatinization enthalpy of the native starch.

\subsubsection{Granule size and distribution}

Particle size determination was carried out at room temperature using a Malvern Master Sizer (Malvern Instruments, Ltd) laser scattering analyser with a $300 \mathrm{~mm}$ Fourier cell (range $0.05 \mu \mathrm{m}$ to $879 \mu \mathrm{m})$. The starch dispersion was first diluted (1/10) with demineralized water at $20^{\circ} \mathrm{C}$ immediately at the end of the Viscograph procedure, then dispersed in the sample dispersion unit ( $1 \mathrm{ml} / 100 \mathrm{ml}$ water) and fed into the measuring cell. Volume distribution was obtained using the Mie scattering theory which requires the refractive index of the media to be specified: we used 1.529 and 1.33 , respectively, for starch and liquid phase and 0.1 for the starch granule absorption (Loisel, Cantoni \& Doublier, 1998). From each distribution, the median volume diameter D(v, 0.5) was chosen to allow comparison with the literature (Ziegler, Thompson \& Casasnovas, 1993) and the size dispersion of starch granules was evaluated using the dispersion index referred to as the span, by the following equation: 


$$
\text { Span: } \frac{D(v, 0.9)-D(v, 0.1)}{D(v, 0.5)}
$$

The same experiment was performed on the starch powder directly after the DIC process to yield the median volume diameter of starch granules.

\subsubsection{Microscopy}

The samples were examined visually using a phase contrast microscope equipped with a CCD camera. Small amounts of sample were suspended in distilled water to $1 / 20$ and observed using a magnification of 400 under direct transmitted or polarized light.

\subsubsection{Experimental design}

A central composite rotatable design with two independent variables and five levels was used. For the two variables, the design yielded 12 experiments with four $\left(2^{2}\right)$ factorial points, four extra points (star points) to form central composite design and four center points for the replications. The experiments were run in random order to minimize the effects of unexpected variability in the observed responses due to extraneous factors. The experimental range and the central point were based on the results of preliminary trials. Table 1 lists the independent variables and the coded factors levels. The response surfaces were obtained by using the analysis design procedure of Statgraphics Plus for Windows, (4.1 version).

\section{Results and discussion}

\subsection{Effect of the DIC treatment on the physical properties of starch}

The effect of the DIC process on the overall physical properties of the two starches is summarized in Tables 2, 3 and 4. Table 2 presents the gelatinization characteristics for the two starches: peak temperature, gelatinization enthalpy and degree of starch gelatinization (\%) induced when applying the DIC process. 
For the two types of starches, the gelatinization temperature as defined by microcalorimetry as the maximum of the endothermic peak did not vary to a large extent when applying the DIC process, unless at the highest pressures. For instance the peak temperature, Tp, jumped from 67.1 (untreated) to $76.6^{\circ} \mathrm{C}$ for SMS, and from 69.7 to $74.5^{\circ} \mathrm{C}$ for WMS, when the $3 \mathrm{bar} / 225 \mathrm{~s}$ process was applied. For milder treatment $(2.7 \mathrm{bar} / 300 \mathrm{~s})$ the change was less dramatic: 70.1 against $67.1^{\circ} \mathrm{C}$ (untreated) for SMS, and 72.5 against $69.7^{\circ} \mathrm{C}$ (untreated) for WMS.

Meanwhile the gelatinization enthalpy decreased progressively for the two types of starches; this decrease was more pronounced beyond 2 bars, particularly for SMS. The gelatinization enthalpy decreased from $11.6 \mathrm{~J} / \mathrm{g}$ (untreated) down to $6.4 \mathrm{~J} / \mathrm{g}(2.7 \mathrm{bar} / 300 \mathrm{~s}$ ) and $2.8 \mathrm{~J} / \mathrm{g}$ (3 bar/ $225 \mathrm{~s})$ for SMS, and from $16.8 \mathrm{~J} / \mathrm{g}$ (untreated) down to $12.7 \mathrm{~J} / \mathrm{g}(2.7 \mathrm{bar} / 300 \mathrm{~s}$ ) and $8.2 \mathrm{~J} / \mathrm{g}$ (3 bar/ $225 \mathrm{~s})$ for WMS.

The decrease of gelatinization enthalpy has been related to loss of crystalline order within the starch granule (Cooke \& Gidley, 1992). This loss of cristallinity, as estimated from DG, was up to $76 \%$ for SMS against $51 \%$ for WMS. This shows that SMS is more sensitive to the DIC treatment than WMS. A progressive loss of cristallinity was experienced as the conditions of the treatment were more intensive.

In spite of lower moisture content of DIC treated starches $(\sim 12 \%)$ compared to moisture content of HMT treated starches $(20 \sim 30 \%)$, quite similar results have been reported in the case of HMT treatment by Takaya et al. (2000) for standard maize starch (at 120 and $130^{\circ} \mathrm{C}$ under saturated humidity for $20 \mathrm{~min})$ and by Lim et al. (2001) $\left(120^{\circ} \mathrm{C}, 1\right.$ hour, $25 \%$ moisture content). These authors observed an increase of the gelatinization peak temperature as well as a decrease of the gelatinization enthalpy. For instance $\mathrm{T}_{\mathrm{p}}$ increased from 66.9 (untreated) to $74.2^{\circ} \mathrm{C}\left(120^{\circ} \mathrm{C}, 25 \%\right.$ moisture content) in the work by Lim et al. (2001), whereas the gelatinization enthalpy decreased from 18.7 to $14.4 \mathrm{~J} / \mathrm{g}$. Hoover and Manuel (1996) also found a shift towards higher temperatures for maize starches: $66^{\circ} \mathrm{C}$ (untreated) against $71^{\circ} \mathrm{C}$, and $73{ }^{\circ} \mathrm{C}$ (untreated) against $74^{\circ} \mathrm{C}$ for SMS 
and WMS, respectively. However, no change was observed in the endothermic value; this difference could be ascribed to the milder process used by these authors: $100^{\circ} \mathrm{C}$ during $16 \mathrm{~h}$ for $30 \%$ hydrated starch.

It has been postulated that the gelatinization enthalpy is related to the overall cristallinity of amylopectin (Tester \& Morrison, 1990). For Cooke and Gidley (1992) the $\Delta \mathrm{H}$ value represents the number of double helices that unravel and melt during gelatinization. The difference of $\mathrm{T}_{\mathrm{p}}$ and $\Delta \mathrm{H}$ between WMS and SMS may be attributed to starch composition, especially the amylose to amylopectin ratio. It is well known that amylopectin is primarily involved in starch granule cristallinity (French, 1984). This may explain why SMS, which contains amylose, is more sensitive to the DIC treatment.

Table 3 gives the median volume diameter before and after pasting in the Viscograph and the Brabender values for the two types of starches. $\mathrm{D}(\mathrm{v}, 0.5)$ obtained before pasting increased with the severity of the treatment. The increase was progressive at first, and then more pronounced for the highest pressures: from $14.5 \mu \mathrm{m}$ to about $67 \mu \mathrm{m}$ for SMS and from $15.7 \mu \mathrm{m}$ to $36 \mu \mathrm{m}$ in the case of WMS. The value for untreated starch corresponds to the usual starch granule size: since starch granules are known not to swell in cold water, the increase of volume diameter may be ascribed to the loss of cristallinity already discussed: the less organized the starch granule, the more hydrated it is. It is worth noting that the largest median diameters of SMS, $52.0 \mu \mathrm{m}(2.7$ bar/300 s) and $66.8 \mu \mathrm{m}(3 \mathrm{bar} / 225 \mathrm{~s})$ are associated to higher span values: 2.2 instead of usual lower values, 1.2 to 1.5 . This heterogeneity of size is due to the presence of larger particles for that samples, probably composed of aggregates of starch granules.

$\mathrm{D}(\mathrm{v}, 0.5)$ of pasted samples exhibit the reverse tendency: the largest size of the granules is obtained for untreated samples, $60.9 \mu \mathrm{m}$ and $39.0 \mu \mathrm{m}$ for SMS and WMS respectively. Then the median diameter decreases from $60.9 \mu \mathrm{m}$ to about $40 \mu \mathrm{m}$ ( $2 \mathrm{bar} / 225 \mathrm{~s})$ for SMS and from $39.0 \mu \mathrm{m}$ to 32.8 $\mu \mathrm{m}(2.7 \mathrm{bar} / 150 \mathrm{~s})$ for WMS. The median diameter of $64.2 \mu \mathrm{m}$ (2 bar/225 s) for SMS being related 
to higher heterogeneity as already mentioned. The decrease of the median diameter of pasted starch granules with increasing DIC conditions, may result from partial disruption of starch granules: the starches which are partially gelatinized by the DIC treatment are more sensitive to the thermal treatment in the Viscograph.

For the two types of results, before and after pasting with the Viscograph, the changes are again dramatic for the most severe treatments. As regards to the calorimetric results, the effect of the treatment differs between SMS and WMS: the later being less prone to swelling.

Figure 1 shows microscopic views of SMS starch granules under polarized light before pasting. The untreated starch (a) exhibited the usual Maltese cross related to its crystalline order. The same observation could be made for the 2 bar/225s treated starch (b). For the view (c) (2.7 bar/300 s), we observed intact starch granules but also starch granules without their Maltese cross. The presence of the later shows partial gelatinization of starch as already mentioned from the calorimetric results. The coexistence of the two types of starch granules may also be related to the heterogeneity in DIC treatment. A recent study pointed out the existence of a gradient of temperature and moisture content between the surface and the bottom of the powder layer (Zarguili, Maache-Rezzoug, Loisel \& Doublier, 2004). Thus the sampling may have an influence on the microscopic observations. The disappearance of the Maltese cross is more pronounced and the proportion of intact granules is smaller for the view (d) (3 bar/225 s). This confirms the loss of cristallinity for the strongest treatments. It is worth noting that even for the most intensive treatment integrity of the starch granule was not altered whereas the size of the starch granules could vary to a large extent (Table 3). For WMS (pictures not shown) there was no dramatic change: the Maltese cross was still observed, whatever the intensity of the treatment. These microscopic observations confirm the higher resistance of WMS to the DIC treatment. 
Figure 2 shows the Brabender viscograms for untreated (a), 2 bar/331 s (b) and 2.7 bar/300s (c) treated SMS. For the two treatments, no peak could be seen and the plateau values clearly were lower.

The peak and plateau values from the viscograms are presented in Table 3. For SMS, the viscosity peak as well as the plateau value dramatically decreased for pressures higher than 2 bars. SMS treated at 2.7 bar during 300 seconds reached the Brabender peak viscosity of 140 BU while for the untreated SMS, the viscosity peak was of 844 BU. For 3 bar/225 s, no viscosity could be measured by this way. This may be explained by disruption of starch granules, as already mentioned from the results of Table 3, the dispersion being extremely fluid. On the opposite way, WMS was much less affected by the hydrothermal treatment.

Typical flow curves of SMS dispersions at $60^{\circ} \mathrm{C}$ are shown in Figure 3 for untreated and DIC treated samples at $6 \%$ concentration $(w / w)$. These flow curves are typical of a non-newtonian shear-thinning fluid with a yield stress as described by Evans and Haisman (1979) and Doublier (1981). The Herschel-Bulkley equation fitted the data satisfactorily $\left(\mathrm{R}^{2}=0.987\right)$, according to the equation (3).

$$
\tau=\tau_{0}+\mathrm{K} \dot{\gamma}^{\mathrm{n}}
$$

Where $\tau_{\mathrm{o}}$ is the yield stress $(\mathrm{Pa}), \mathrm{K}$ the consistency index $\left(\mathrm{Pa} . \mathrm{s}^{\mathrm{n}}\right)$ and $\mathrm{n}$ the flow behavior index (dimensionless).

As seen in Table 4 the apparent viscosity at a shear rate of $1 \mathrm{~s}^{-1}$ and the yield stress values for SMS first decreased for the mildest DIC treatment; this was followed by a slight increase and then a decrease beyond 2 bar/119 s. For the 3 bar/225 s treated SMS, the behavior was also shearthinning, but no yield stress was detected, owing to the fluidity of the paste $\left(0.09\right.$ Pas at $\left.1 \mathrm{~s}^{-1}\right)$. For WMS, the Herschel-Buckley equation was obeyed $\left(\mathrm{R}^{2}=0.983\right)$ but no strong effect of the treatment was noticed. 
Figure 4 illustrates the viscoelastic behavior at $60^{\circ} \mathrm{C}$ of $6 \%$ native and $2.7 \mathrm{bar} / 300 \mathrm{~s}$ treated SMS dispersion through the variations of the storage modulus $\left(G^{\prime}\right)$ and the loss modulus $\left(G^{\prime \prime}\right)$ as a function of frequency. The native starch exhibited the behavior of a weak gel with G'> G' and G' almost independent of frequency. The SMS treated sample displayed lower and more frequencydependent moduli, but the behavior remained solid-like. As can be seen from Table 4, the storage modulus dramatically dropped for the 2.7 bar/300 s treated starch and completely disappeared for the $3 \mathrm{bar} / 225 \mathrm{~s}$ experiment. In this case the starch paste was extremely fluid. With respect to the waxy maize starch, no change of the moduli was observed after the DIC treatment.

The rheological behavior of starch suspensions is known to be the result of a combination of two major factors: the continuous phase and the volume fraction of the dispersed phase. In the range of concentrations used in this work, the volume fraction appears to be close to unity: the suspension can then be described as a packing of swollen starch granules, the overall behavior being governed by the dispersed phase (Doublier, Llamas \& Le Meur, 1987). This explains why the elastic response in the viscoelastic behavior of the suspension is predominant (Tecante \& Doublier, 1999). In such a case, the deformability of the swollen starch granules also plays a role in the rheological properties: the decrease of apparent viscosity and storage modulus with the intensity of the treatment may be related to a higher deformability.

Figure 5 shows changes with time of the storage modulus measured at $25{ }^{\circ} \mathrm{C}$ for untreated SMS starch and treated at 2.7 bar during $150 \mathrm{~s}$ and $300 \mathrm{~s}$. For untreated starch, the increase in $\mathrm{G}^{\prime}$ is the result of amylose gelation which takes place in the continuous phase of the starch dispersion at $25^{\circ} \mathrm{C}$. As a result, the starch gel can be regarded as a composite of swollen granules embedded in a solid matrix. For the treated starch, the occurrence of amylose gelation is attested by the increase of $G^{\prime}$ as a function of time for both treatments; the time of the treatment modifies the $G^{\prime}$ value on a significant way, by decreasing the G' value. The lower G' values may result of the combination of different parameters such as: increased deformability of starch granules or lower elasticity of 
the continuous phase. This latter phenomenon would be related to lower ability to form a gel of the amylose in the continuous phase.

To conclude, the Viscograph procedure which is a mean to characterize the starch paste under repeatable conditions produces a dramatic decrease of apparent viscosity and storage modulus of SMS starch previously treated under the most severe DIC conditions. This can be related to the partial gelatinization of SMS obtained through the DIC treatment, which makes it more sensitive to the thermal treatment in the Viscograph and leads to partial disruption of starch granules.

\subsection{Statistical analysis}

Among the response parameters cited in Tables 2, 3 and 4 for SMS, we selected three representative ones namely $D_{v}, \Delta H$ and $\eta_{a}$ for statistical considerations.

The relationship between the processing parameters and the responses can be explained by examining the response surfaces generated by the second order polynomial equation obtained from the experimental analysis (Fig. 6 for SMS). A second degree polynomial equation was assumed to approximate the considered response:

$\mathrm{R}_{\mathrm{p}}=\beta_{0}+\beta_{1} x_{1}+\beta_{2} x_{2}+\beta_{11} x_{1}^{2}+\beta_{22} \mathrm{x}_{2}^{2}+\beta_{12} x_{1} x_{2}$

Where $\mathrm{R}_{\mathrm{p}}$ is the considered response, $\beta_{0}, \beta_{1}, \beta_{2}, \beta_{11}, \beta_{11}$ and $\beta_{12}$ the regression coefficients and $x_{1}$, $x_{2}$, the variables related respectively to pressure level and processing time. The regression coefficients are showed in Table 5. Adequacy tests of the models, tested by the coefficients of determination $\mathrm{R}^{2}$, revealed that they were quite well adequate with a probability of rejecting the lack of fit greater than 0.05 .

The results of statistical analysis are given in Table 6 indicating the p-value and the F-ratio for each response parameter. P-value less than 0.05 indicates that the source (linear, quadratic or cross product term) is significantly different from zero at the $95 \%$ confidence level, based on Fisher test. From this Table, it can be clearly seen that the steam pressure level is the most significant parameter. 
From Figure 6a, it can be seen that the linear and quadratic effects of the steam pressure level are very pronounced for $D_{v}$ which increases from 13 to $43 \mu \mathrm{m}$ when the pressure level increased from 1.3 to 2.7 bar; in the meantime, the variation of $D_{v}$ for increasing processing time from $150 \mathrm{sec}$ $300 \mathrm{sec}$ is only from 13 to $23 \mu \mathrm{m}$. The increase of the pressure level induces an increase of the median volume diameter especially for high values of processing time. This is confirmed by a significant effect of the two-factor interaction illustrated by a distortion of the response surface.

A similar trend is observed for $\Delta \mathrm{H}$ for which the steam pressure level has a strong effect. Figure $6 \mathrm{~b}$ shows that the gelatinization enthalpy is directly proportional to steam pressure level, this being the only significant parameter. The higher the steam pressure, the lower the $\Delta H$ value. $\Delta H$ decreases from 11.2 to $6.2 \mathrm{~J} / \mathrm{g}$ when the steam pressure level varies from 1.3 to $2.7 \mathrm{bar}$ (Figure 6b). The processing time is not a critical parameter, since an increase from 150 to 300 seconds yields a decrease of enthalpy of only 10 to $9.2 \mathrm{~J} / \mathrm{g}$.

The apparent viscosity (Figure 6c) depends not only on the steam pressure level (linear and quadratic significant effects) but also on the processing time. This response decreases with both steam pressure level (beyond 1.6 bar) and processing time.

The analysis of other parameters (not shown) displays a predominance of steam pressure level effect compared to that of processing time. 


\section{Conclusion}

Starch can be modified by Instantaneous Controlled Pressure Drop (Détente Instantanée Contrôlée: DIC) treatment, starch granules being exposed to high temperature obtained by steam under pressure during short time period $(<10 \mathrm{~min})$. DIC treatment of starch can be defined as a physical modification that involves treatment at very restricted moisture content $(\sim 12 \%)$. The DIC process revealed itself to be an interesting technique to obtain partially pre-gelatinized starches without subsequent drying of the product. The methods employed to estimate the physical changes i.e. microcalorimetry, particle size and microscopic analysis, attested the progressive loss of cristallinity while starch granules were not ruptured. These changes became dramatic for the strongest processing conditions: 2.7 to 3 bars for 200 to 300 seconds. The DIC treatment yielded an increased fluidity and a loss of the elastic response of the pastes, as a result of partial pregelatinization of starch granules brought about by the process. We also noticed a marked difference in the sensitivity of the two types of starches to the process, SMS being more affected than WMS. For WMS, prolonged processing times or higher steam pressure are probably required to obtain a same gelatinization degree as SMS. 


\section{References}

Anastasiades, A., Thanou, S. Loulis, D., Stapatoris, A., Karapantsios, T.D. (2002). Rheological and physical characterization of pregelatinized maize starches. Journal of Food Engineering, 52, 57-66.

Chung, H.J. \& Lim, S.T. (2003). Physical aging of glassy normal and waxy rice starches: effects of aging temperature on glass transition and enthalpy relaxation. Carbohydrate Polymers, 53, 205211.

Cooke, D., \& Gidley, M.J. 1992. Loss of crystalline and molecular order during starch gelatinization and origin of the enthalpic transition. Carbohydrate research, 227, 103-112.

Donovan, J.W., Lorenz, K., \& Kulp, K. (1983). Differential scanning calorimetry of heat-moisture treated wheat and potato starches. Cereal Chemistry, 60 (5), 381-387.

Doublier, J.L. (1981). Rheological studies on starch - Flow behaviour of wheat starch pastes. Starch/Stärke, 33, 415-420.

Doublier, J.L., Llamas, G. \& Le Meur M. (1987). A rheological investigation of cereal starch pastes and gels. Effect of pasting procedures. Carbohydrate Polymers, 7, 251-275.

Eliasson, A.C., Larsson, K. (1993). Cereals in breadmaking. A molecular colloidal approach. (pp. 96-129). Marcel Dekker Inc., New York.

Evans, I. D. \& Haisman, D.R. (1979). Rheology of gelatinized starch suspensions. Journal of Texture Studies, 23, 69-86.

French, D. (1984). Organization of starch granules. In R. L. Whistler, J. N. Be Miller \& E. F. Pascall, Starch Chemistry and Technology (pp. 183-247). Academic Press, New York.

Gunaratne, A. \& Hoover, R. (2002). Effect of heat-moisture treatment on the structure and physicochemical properties of tuber and root starches. Carbohydrate Polymers, 49, 425-437.

Hoover, R. \& Manuel, H. (1996). The effect of heat-moisture treatment on the structure and physicochemical properties of normal maize, waxy maize, dull waxy maize and amylomaize $\mathrm{V}$ starches. Journal of Cereal Sciences, 23, 153-162.

Hoover, R. (2001). Composition, molecular structure, and physico-chemical properties of tuber and root starches: a review. Carbohydrate Polymers, 45, 253-267.

Kiseleva, V.I., Tester, R F., Wasserman, L.A., Krivandin, A.V., Popov, A.A, Yurvev, V.P. (2003). Influence of growth temperature on the structure and thermodynamic parameters of barley starches. Carbohydrate Polymers, 51, 407-415.

Lim, S.T., Chang, E.H., Chung, H.J. (2001) Thermal transition characteristics of heat treated corn and potato starches. Carbohydrate Polymers, 46, 107-115.

Loisel, C., Cantoni, P. \& Doublier, J.L. (1998). Structure des empois d'amidon en relation avec leur comportement rhéologique. In AGORAL 98, Structuration des aliments, Lavoisier Eds, 450455 . 
Maache-Rezzoug, Z., \& Allaf, K. (1999). Effect of instantaneous controlled pressure drop treatment on organoleptic and cooking quality of pasta products. In ECC2- Second European Congress of Chemical Engineering - Montpellier.

Marshall, W. E., Wadsworth, J. I., Verma, L. R., Velupillai, L. (1993). Determining the degree of gelatinization in parboiled rice: comparison of subjective and an objective method. Cereal Chemistry, 70, 226-230.

Mercier, C. 1987. Comparative modifications of starch and starchy products by extrusion cooking and drum-drying. In C. Mercier, C. Cantarelli (Eds), Pasta and extrusion cooked foods (pp. 120130). Elsevier, London.

Rezzoug, S.A., Maache-Rezzoug, Z., Mazoyer, J, Jeannin, M., Allaf K. (2000). Effect of instantaneous controlled pressure drop proccess on hydration capacity of scleroglucan. Optimisation of operating conditions by response surface methodology. Carbohydrate Polymers, 42, 73-84.

Takaya, T., Sano, C., Nishinari, K. (2000). Thermal studies on the gelatinization and retrogradation of heat-moisture treated starch. Carbohydrate Polymers, 41, 97-100.

Tecante, A. \& Doublier, J.L. (1999). Steady flow and viscoelastic behavior of crosslinked waxy corn starch-K-carrageenen pastes and gels. Carbohydrate Polymers, 40, 221-223.

Tester, R.F. \& Morrison, W. R. (1990). Swelling and gelatinization of cereal starches. I. Effect of amylopectin, amylose and lipids. Cereal Chemistry, 67, 551-559.

Tester, R. F. \& Debon, S. J. J. (2000). Annealing of starch. International Journal of biological Macromolecules, 27, 1-12.

Vallous, N. A, Gavrielidou, M.A., Karapantsios, T.D., Kostoglou, M. (2002). Performance of a double drum dryer for producing pregelatinized maize starches. Journal of Food Engineering, 51, 171-183.

Williams, M.R., \& Bowler, P. (1982). Starch gelatinization : a morphological study of triticeae and other starches. Starch/Stärke, 34, 221-223.

Zarguili, I., Maache-Rezzoug, Z., Loisel, C., Doublier, J.L., 2004. Study of the effect of hydrothermal process conditions on the properties of maize starch. In $16^{\text {th }}$ international Congress of Chemical and Process Engineering - Prague - Czech Republic.

Ziegler, G.R., Nordmark, T.S., Woodling, S.E. (2003). Spherulitic crystallization of starch : influence of botanical origin and extent of thermal treatment. Food Hydrocolloids, 17, 487-495.

Ziegler, G.R., Thompson, D.B., \& Casasnovas, J. (1993). Dynamic measurement of starch granule swelling during gelatinization. Cereal Chemistry, 30 (3), 247-251. 


\section{Figures captions}

Figure 1. Microscopic observations of SMS: untreated (a); DIC treated at 2bar/225s (b), at 2.7bar/300s (c) and at 3 bar/225 (d). Scale bar: $50 \mu \mathrm{m}$.

Figure 2. Pasting profiles obtained with the Brabender Viscograph of SMS: untreated (a); DIC treated at $2 \mathrm{bar} / 331 \mathrm{~s} \mathrm{(b)}$ and at $2.7 \mathrm{bar} / 300 \mathrm{~s}(\mathrm{c})$.

Figure 3. Flow curves of $6 \% \mathrm{SMS}$ dispersion (measurement at $\left.60{ }^{\circ} \mathrm{C}\right) .(\diamond)$ ): untreated starch; (๑): DIC treated at $1 \mathrm{bar} / 225 \mathrm{~s} ;(\boldsymbol{\nabla})$ : DIC treated at $2.7 \mathrm{bar} / 300 \mathrm{~s}$. The continuous line represents the regression curve according to Herschel-Buckley equation.

Figure 4. Mechanical spectra of $6 \%$ SMS dispersion (measurement at $60{ }^{\circ} \mathrm{C}$; shear strain $4 \%$ ). G' (solid), G" (hollow); $(\diamond)$ : untreated starch; ( $\boldsymbol{\square})$ : DIC treated at $2.7 \mathrm{bar} / 300 \mathrm{~s}$.

Figure 5. G' variations at $25{ }^{\circ} \mathrm{C}$ as a function of time of $6 \%$ SMS dispersions. (shear strain $4 \%$; angular frequency: $6.3 \mathrm{rad} / \mathrm{s}) .(\diamond)$ : untreated starch; $(\mathbf{\Delta})$ : DIC treated at $2.7 \mathrm{bar} / 150 \mathrm{~s}$; $(\boldsymbol{\square})$ : DIC treated at $2.7 \mathrm{bar} / 300 \mathrm{~s}$.

Figure 6. Response surfaces plots for SMS as a function of the hydrothermal processing parameters. 
Figure 1

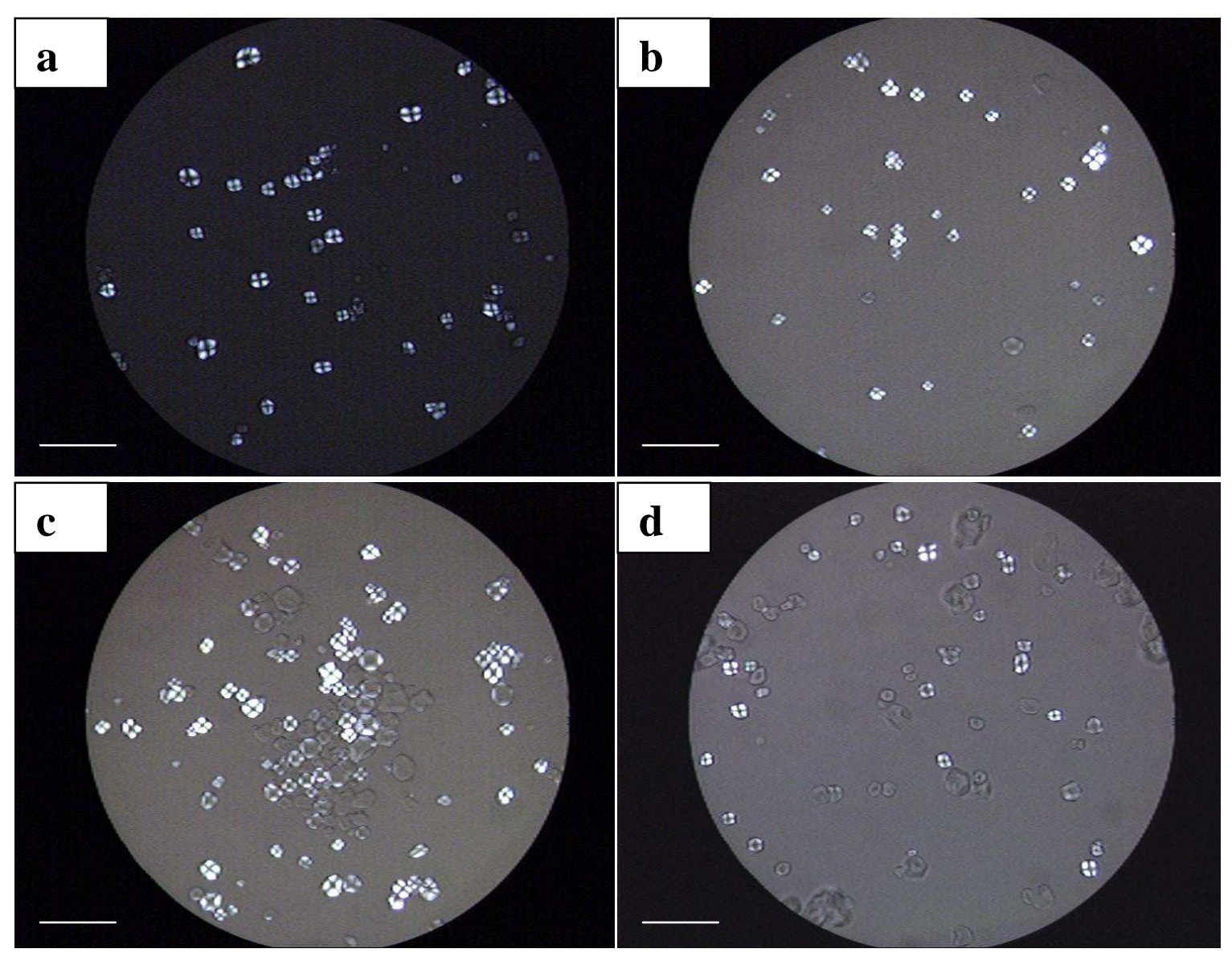


Figure 2

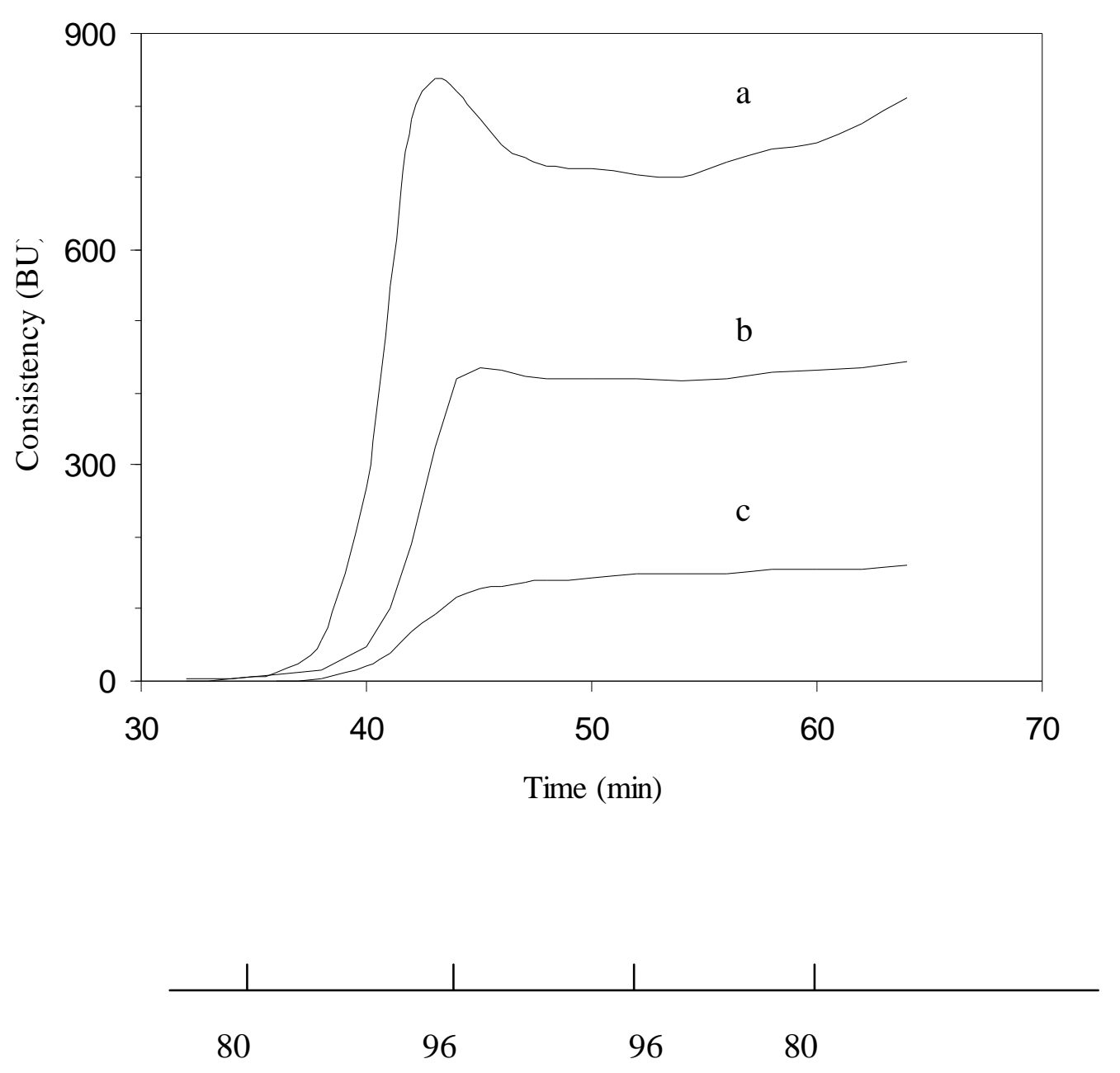

Temperature $\left({ }^{\circ} \mathrm{C}\right)$ 
Figure 3

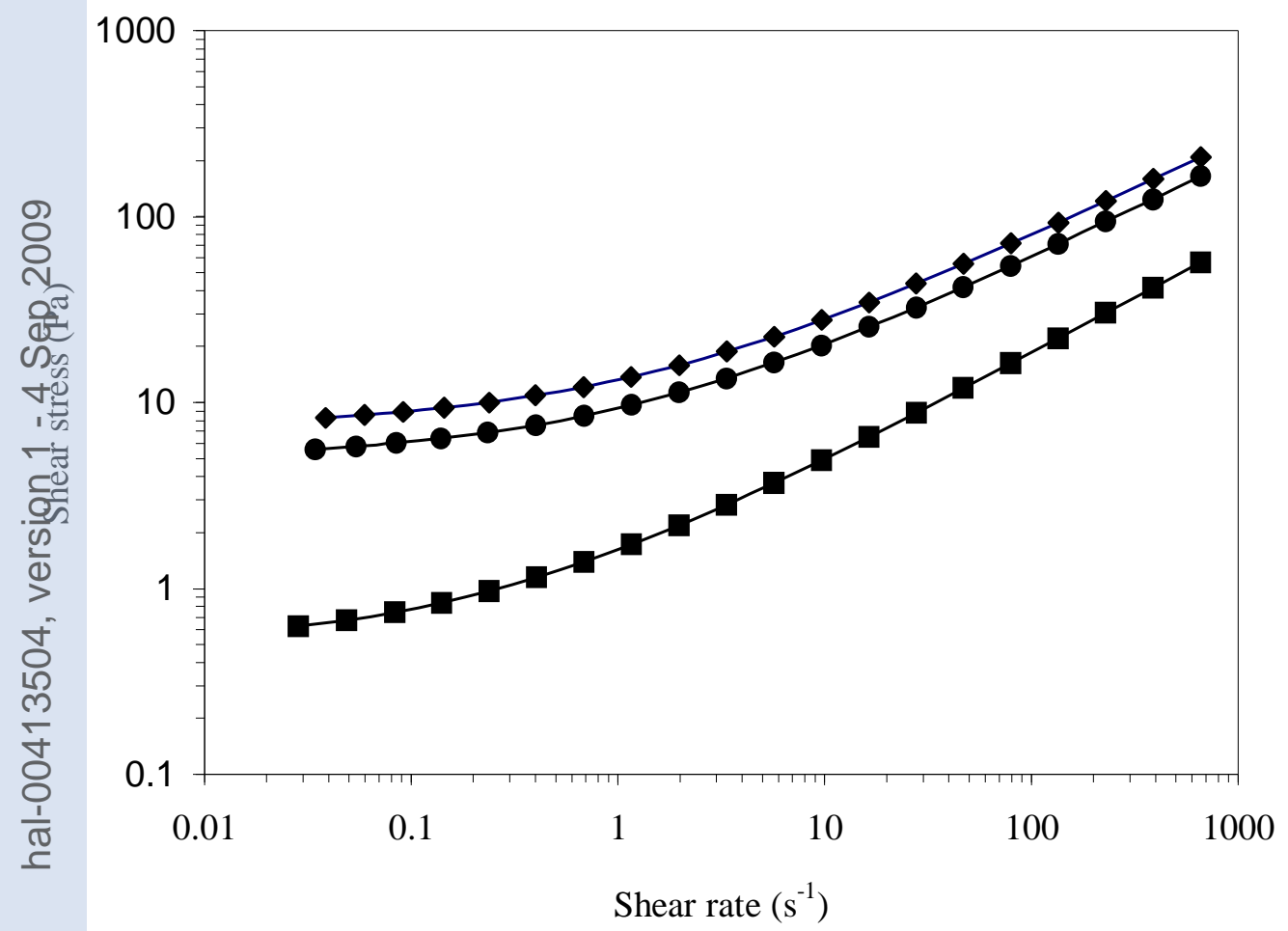


Figure 4

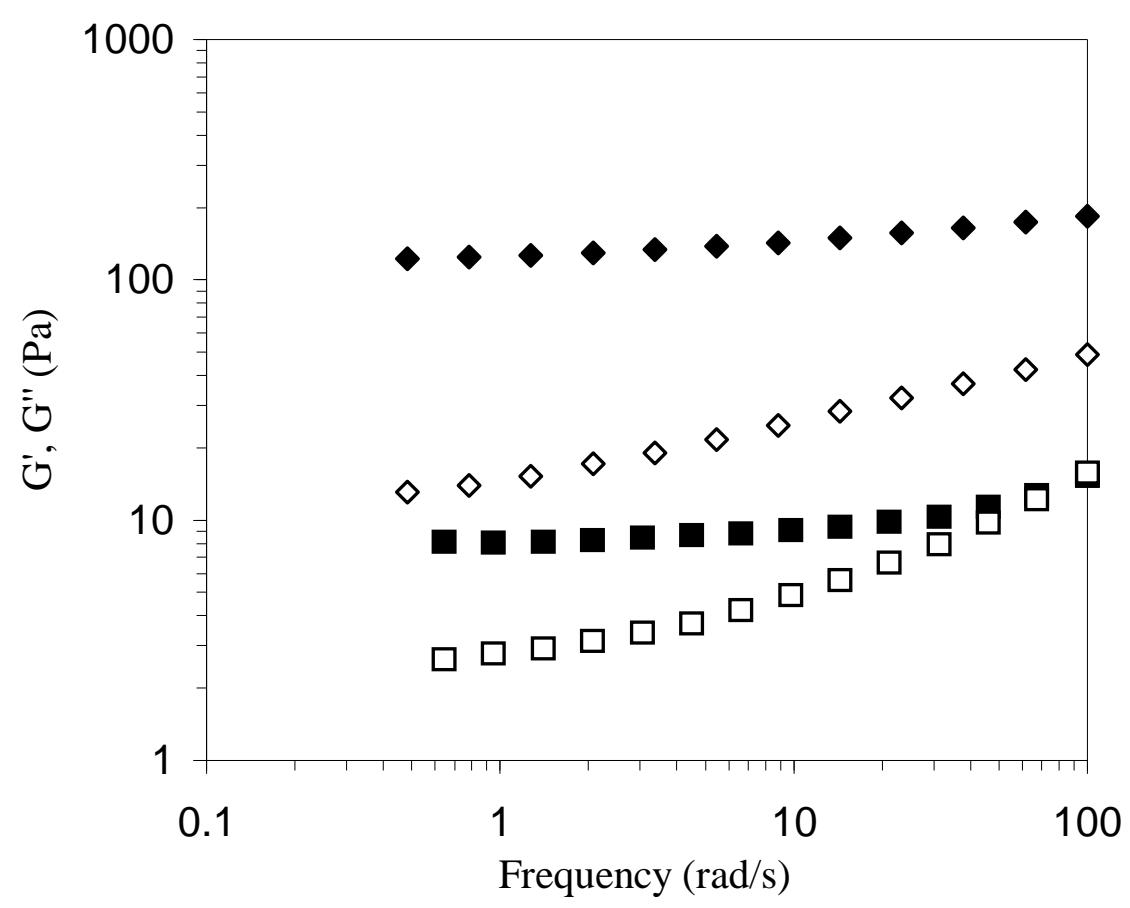


Figure 5

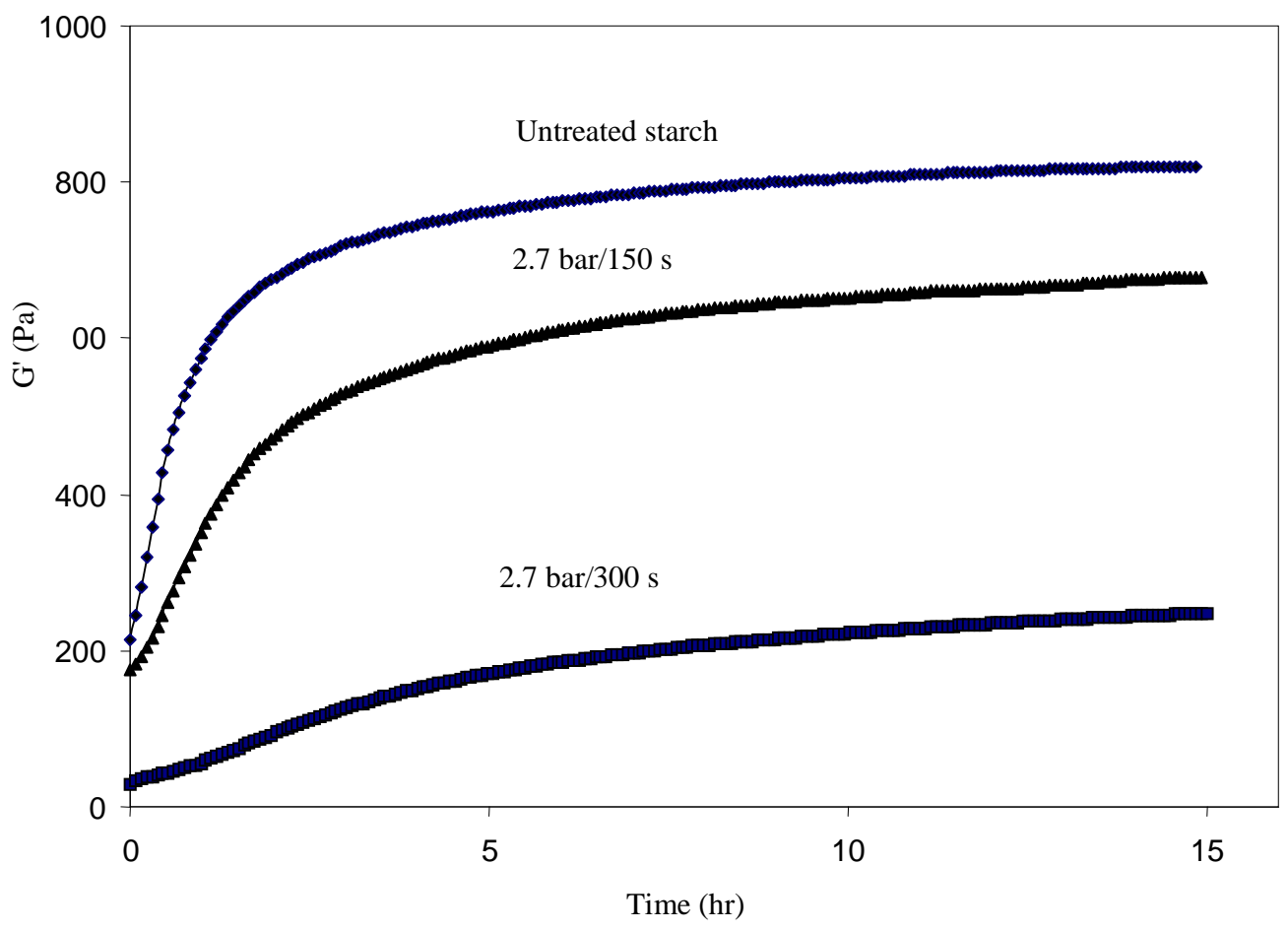




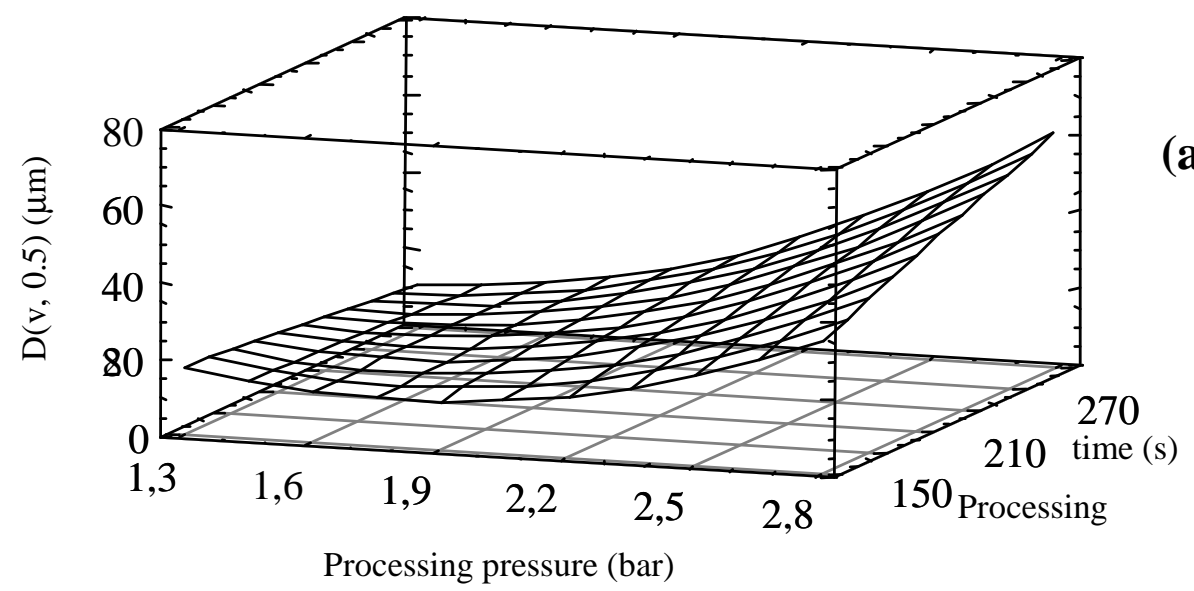

(a)

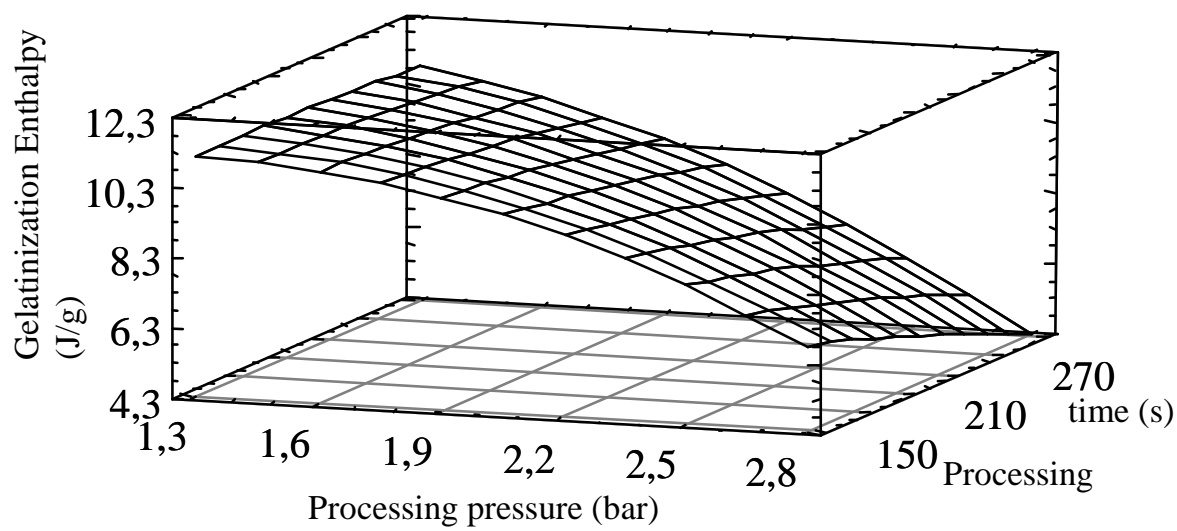

(b)

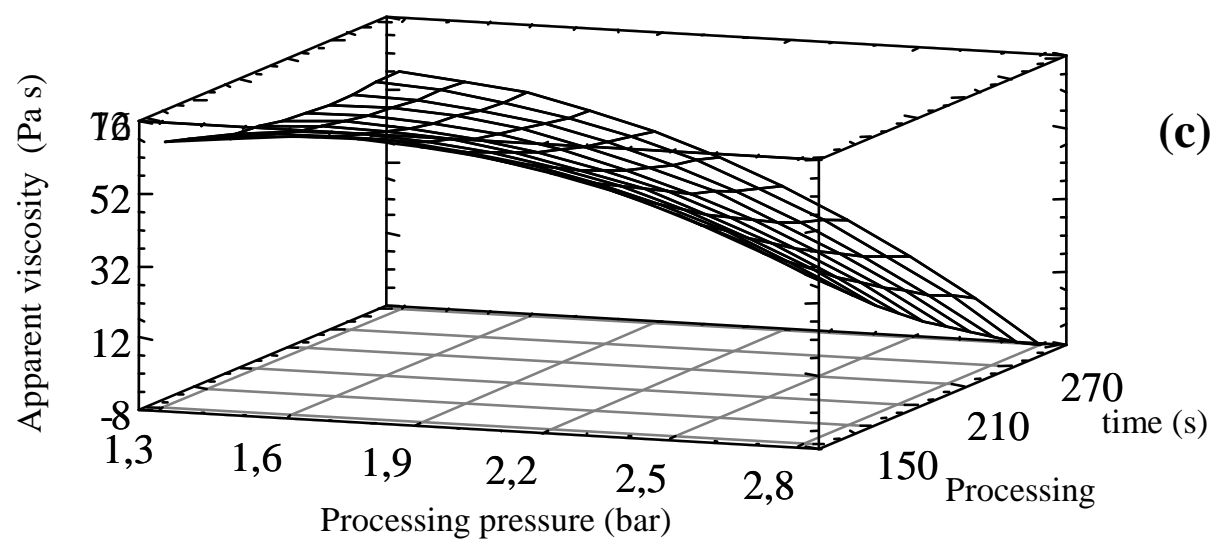

Figure 6 
Table 1: Coded levels for independent variables used in developing experimental data

\begin{tabular}{llllll}
\hline & \multicolumn{5}{c}{ Coded level } \\
\cline { 2 - 6 } & $-\alpha$ & -1 & 0 & 1 & $+\alpha$ \\
\hline Pressure level (bar) & 1.0 & 1.3 & 2 & 2.7 & 3.0 \\
Processing time (s) & 119 & 150 & 225 & 300 & 331 \\
\hline
\end{tabular}

$\alpha($ Axial distance $) \sqrt[4]{\mathrm{N}}, \mathrm{N}$ is the number of experiments of orthogonal design, i.e. of the factorial design. In this case $\alpha=1.414$. 
Table 2: DSC characteristics of SMS and WMS after DIC process

\begin{tabular}{ccccccc}
\hline $\begin{array}{c}\text { Processing } \\
\text { Parameters }\end{array}$ & \multicolumn{3}{c}{ Standard Maize Starch } & \multicolumn{3}{l}{ Waxy Maize Starch } \\
\hline $\begin{array}{c}\text { Steam pressure level } \\
\text { (bar)/time }(\mathrm{s})\end{array}$ & $\begin{array}{c}\mathrm{T}_{\mathrm{p}} \\
\left({ }^{\circ} \mathrm{C}\right)\end{array}$ & $\begin{array}{c}\Delta \mathrm{H} \\
(\mathrm{J} / \mathrm{g})\end{array}$ & $\mathrm{DG}^{(1)}(\%)$ & $\begin{array}{c}\mathrm{T}_{\mathrm{p}} \\
\left({ }^{\circ} \mathrm{C}\right)\end{array}$ & $\begin{array}{c}\Delta \mathrm{H} \\
(\mathrm{J} / \mathrm{g})\end{array}$ & $\mathrm{DG}^{(1)}(\%)$ \\
\hline Untreated & 67.1 & 11.6 & - & 69.7 & 16.8 & 0 \\
\hline $1 / 225$ & 67.1 & 11.5 & 1.2 & 69.8 & 15.9 & 5.3 \\
\hline $1.3 / 150$ & 67.3 & 11.2 & 3.5 & 70.0 & 16.0 & 4.8 \\
\hline $1.3 / 300$ & 67.5 & 11.0 & 5.1 & 70.5 & 15.4 & 8.3 \\
\hline $2 / 119$ & 68.5 & 9.5 & 18.1 & 70.4 & 15.2 & 9.2 \\
\hline $2 / 225^{(2)}$ & $69.1(0.2)$ & $9.6(0.3)$ & $17.2(2.4)$ & $71.2(0.47)$ & $14.8(0.4)$ & $11.9(2.4)$ \\
\hline $2 / 331$ & 69.7 & 7.8 & 32.8 & 72.1 & 14.9 & 11.1 \\
\hline $2.7 / 150$ & 68.1 & 8.6 & 25.5 & 70.9 & 13.8 & 18.0 \\
\hline $2.7 / 300$ & 70.1 & 6.4 & 45.0 & 72.5 & 12.7 & 24.1 \\
\hline $3 / 225$ & 76.6 & 2.8 & 76.3 & 74.5 & 8.2 & 51.3 \\
\hline
\end{tabular}

${ }^{(1)}$ DG, starch gelatinization of DIC treated starch; ${ }^{(2)}$ Mean absolute error (five repetitions); - too low to be measured. 
Table 3: Particle size and Brabender characteristics of SMS and WMS after DIC process

\section{Standard Maize Starch Waxy Maize Starch}

\begin{tabular}{ccccccc}
\hline $\begin{array}{c}\text { Processing } \\
\text { Parameters }\end{array}$ & Particle size & \multicolumn{2}{c}{ Brabender $6 \%$ at $96^{\circ} \mathrm{C}$} & Particle size $^{(1)}$ & Brabender 3\% at $96^{\circ} \mathrm{C}$ \\
\hline $\begin{array}{c}\text { Steam pressure } \\
\text { level (bar)/time (s) }\end{array}$ & $\begin{array}{c}\mathrm{D}(\mathrm{v}, 0.5)^{(2)} \\
\text { before }- \text { after } \\
\text { pasting }(\mu \mathrm{m})\end{array}$ & $\begin{array}{c}\text { Peak } \\
\mathrm{BU}\end{array}$ & $\begin{array}{c}\text { Plateau } \\
\mathrm{BU}\end{array}$ & $\begin{array}{c}\mathrm{D}(\mathrm{v}, 0.5)^{(2)} \\
\text { before }- \text { after } \\
\text { pasting }(\mu \mathrm{m})\end{array}$ & $\begin{array}{c}\text { Peak } \\
\mathrm{BU}\end{array}$ & $\begin{array}{c}\text { Plateau } \\
\mathrm{BU}\end{array}$ \\
\hline Untreated & $14.5-60.9$ & 844 & 716 & $15.7-39.0$ & 680 & 384 \\
\hline $1 / 225$ & $15.4-51.4$ & 848 & 716 & $15.7-35.4$ & 604 & 400 \\
\hline $1.3 / 150$ & $16.8-41.2$ & 848 & 716 & $15.9-36.7$ & 636 & 412 \\
\hline $1.3 / 300$ & $17.4-50.5$ & 836 & 716 & $17.0-36.9$ & 588 & 404 \\
\hline $2 / 119$ & $17.6-64.2$ & 760 & 676 & $18.3-36.8$ & 636 & 404 \\
\hline $2 / 225^{(3)}$ & $18.5(0.5)-39.7$ & $756(28.7)$ & $669(19)$ & $16.9(0.7)-36.8$ & $646(25)$ & $424(18)$ \\
\hline $2 / 331$ & $21.7-36.4$ & 440 & 416 & $16.7-37.0$ & 598 & 396 \\
\hline $2.7 / 150$ & $20.8-40.5$ & 580 & 524 & $22.3(4)-32.8$ & 644 & 428 \\
\hline $2.7 / 300$ & $52.0-35.4$ & 140 & 148 & $19.2-32.0$ & 548 & 388 \\
\hline $3 / 225$ & $66.8-40.0$ & - & - & $36.0-26.1$ & 504 & 356 \\
\hline
\end{tabular}

${ }^{(1)}$ Before and after pasting with the Viscograph; ${ }^{(2)}$ average of three repetitions; ${ }^{(3)}$ Mean absolute error (five repetitions); (4) high variability; - : too low to be measured. 
Table 4: Rheological properties of SMS and WMS after DIC treatment.

SMS Rheological properties at $6 \%$

WMS Rheological properties at $3 \%$

\begin{tabular}{|c|c|c|c|c|c|c|c|c|c|c|c|c|}
\hline \multirow{2}{*}{$\begin{array}{l}\text { Processing } \\
\text { parameters } \\
\text { Steam pressure }\end{array}$} & \multirow[b]{2}{*}{$\tau_{0}$} & \multicolumn{2}{|c|}{$\begin{array}{c}\text { Flow behavior } \\
60^{\circ} \mathrm{C}\end{array}$} & \multicolumn{3}{|c|}{$\begin{array}{l}\text { Viscoelasticity } \\
60^{\circ} \mathrm{C}, 6.3 \mathrm{rad} / \mathrm{s}\end{array}$} & \multirow[b]{2}{*}{$\tau_{0}$} & \multicolumn{3}{|c|}{$\begin{array}{c}\text { Flow behavior } \\
60^{\circ} \mathrm{C}\end{array}$} & \multicolumn{2}{|c|}{$\begin{array}{l}\text { Viscoelasticity } \\
60^{\circ} \mathrm{C}, 6.3 \mathrm{rad} / \mathrm{s}\end{array}$} \\
\hline & & $\mathrm{K}$ & $\mathrm{n}$ & $\eta$ & $\mathrm{G}^{\prime}$ & G" & & $\mathrm{K}$ & $\mathrm{n}$ & $\eta$ & $\mathrm{G}^{\prime}$ & G" \\
\hline (bar)/time (s) & $(\mathrm{Pa})$ & $\left(\mathrm{Pa} \mathrm{s}^{\mathrm{n}}\right)$ & & $(\mathrm{Pa} \mathrm{s})^{(1)}$ & $(\mathrm{Pa})$ & $(\mathrm{Pa})$ & $(\mathrm{Pa})$ & $\left(\mathrm{Pa} \mathrm{s}^{\mathrm{n}}\right)$ & & $(\text { Pa.s })^{(1)}$ & $(\mathrm{Pa})$ & $(\mathrm{Pa})$ \\
\hline Untreated & 7.27 & 5.98 & 0.54 & 12.36 & 137.6 & 21.70 & 1.11 & 0.97 & 0.55 & 1.90 & 1.90 & 1.08 \\
\hline $1 / 225$ & 4.94 & 4.37 & 0.55 & 8.61 & 130.3 & 23.16 & 1.20 & 0.96 & 0.55 & 1.93 & 1.94 & 1.04 \\
\hline $1.3 / 300$ & 9.29 & 4.33 & 0.56 & 12.64 & 153.1 & 20.60 & 1.28 & 1.00 & 0.55 & 2.04 & 2.32 & 1.12 \\
\hline $2 / 119$ & 10.39 & 5.64 & 0.53 & 15.75 & 174.6 & 23.24 & 1.44 & 1.19 & 0.54 & 2.36 & 2.13 & 1.14 \\
\hline $2 / 225^{(2)}$ & 6.51 & 4.74 & 0.53 & 10.79 & 144.7 & 18.99 & 1.28 & 1.05 & 0.55 & 2.10 & 2.31 & 1.15 \\
\hline $2 / 331$ & 3.61 & 2.72 & 0.55 & 5.78 & 108.8 & 13.88 & 1.23 & 1.05 & 0.55 & 2.05 & 2.34 & 1.19 \\
\hline $2.7 / 150$ & 5.33 & 2.74 & 0.59 & 7.58 & 116.2 & 16.52 & 1.23 & 1.02 & 0.55 & 2.02 & 2.49 & 1.42 \\
\hline
\end{tabular}

(1) Apparent viscosity measured at $1 \mathrm{~s}^{-1}$; ${ }^{(2)}$ Average of five repetitions 
Table 5: Regression coefficients of the polynomial function (the values of the variables are specified in their original units) and the coefficients of determination

\begin{tabular}{cccc}
\hline Coefficients & $\begin{array}{c}\text { Apparent } \\
\text { viscosity }\end{array}$ & Enthalpy & $\mathrm{D}(\mathrm{v}, 0,5)$ \\
\hline$\beta_{0}$ & -7.36 & 5.52 & 113.58 \\
$\beta_{1}$ & 26.03 & 6.03 & -98.69 \\
$\beta_{2}$ & 0.00 & 0.02 & -0.21 \\
$\beta_{11}$ & -6.07 & -1.82 & 21.44 \\
$\beta_{12}$ & -0.03 & 0.01 & 0.14 \\
$\beta_{22}$ & 0.00 & 0.00 & 0.00 \\
\hline $\mathrm{R}^{2}$ & $91.74 \%$ & $88.15 \%$ & $91.45 \%$ \\
\hline
\end{tabular}


Table 6: Analysis of variance showing the effect of treatment variables as a linear term, quadratic term and interactions (cross product) on the response parameters for SMS

\begin{tabular}{lcccccc}
\hline & \multicolumn{2}{c}{ Apparent viscosity } & \multicolumn{2}{c}{ Enthalpy } & \multicolumn{2}{c}{$\mathrm{D}(\mathrm{v}, 0,5)$} \\
\hline Source & F-ratio & P-value & F-ratio & P-value & F-ratio & P-value \\
\hline $\mathrm{P}$ & 53.04 & $0.0002^{*}$ & 43.36 & $0.0003^{*}$ & 42.25 & $0.0003^{*}$ \\
$\mathrm{t}$ & 27.00 & $0.0013^{*}$ & 2.68 & 0.1456 & 4.86 & 0.0632 \\
$\mathrm{PP}$ & 32.94 & $0.0007^{*}$ & 5.07 & 0.0591 & 20.94 & $0.0026^{*}$ \\
$\mathrm{Pt}$ & 5.34 & 0.0542 & 0.99 & 0.3533 & 6.39 & $0.0393^{*}$ \\
$\mathrm{tt}$ & 0.20 & 0.6670 & 0.10 & 0.7660 & 0.01 & 0.9192 \\
\hline
\end{tabular}

* indicates significant at $\mathrm{p}<0.05$. $\mathrm{P}$ : steam pressure level; $\mathrm{t}$ : processing time 